\title{
Where next with peer-review?
}

Next week's conference at Chicago on the peer-review system as it applies to journals will rehearse old discontents about the system, but should also ask whether pressures on the system now can be sustained.

THERE seems to be a paradox at the heart of what is called the 'peer-review' process: researchers wishing to see their work in print prefer that it should appear in journals that send research articles they consider seriously to outside referees for appraisal and criticism, but are then frequently deeply offended if publication is refused in the light of what the referees may say.

But the seeming paradox is not a paradox at all. Rather, the umbrage caused by refused publication on these grounds may be likened to the resentment of the practice, in the old days, by which exclusive clubs would allow existing members to veto (or 'black-ball') new applicants for membership. To be accepted by one's peers is naturally preferable to acceptance by a group of people drawn at random and, conversely, to be rejected by them is doubly hurtful.

But there is more to peer-review than the apportionment of amour propre, as can be told from the programme for the meeting, billed as the International Congress on Peer Review in Biomedical Publication, which has been organized by the American Medical Association at Chicago next week. Perhaps inevitably, the peerreview process as such has become a subject of academic study. How consistent with each other are referees' opinions? Does the intervention of referees in the publication process bias the literature, perhaps in a conservative direction? How well do referees' opinions stand up to the passage of time? These are interesting questions, even if their relevance to the process of publication is not easily fathomed.

One difficulty is that the origins of the peer-review system are obscure. Half a century or so ago, most of the journals making up the then much smaller bulk of the scientific literature were published by scientific societies which, having appointed a board of editors consisting of people knowledgeable in the field, would trust them to decide what should be printed. Vestiges of that system persist, although the editorial boards of most journals have found it increasingly necessary to seek outside advice. Their collective expertise, however great, will not always allow sure judgements on questions such as whether a particular technique has been correctly carried out, or is an appropriate foundation for the inferences drawn from the data it provides.
General journals such as this, without a formal board of expert editors, naturally have an even more urgent need of outside advice, but usually have been slow to seek it. So much can be told by glancing at volumes of Nature dating from as recently as the 1950s. A little reflection, for example, will show that the brief letter in which J. D. Watson and F. H. C. Crick described what turned out to be the correct molecular structure of DNA (171, $737 ; 1953$ ) could not have been through a particularly stringent review process.

There is internal evidence - the interval between submission (on 2 April) and publication (25 April) can hardly have left much time for careful scrutiny and criticism. The original article also includes statements that would not now survive in the hands of referees. Watson and Crick described a structure arrived at by modelbuilding, adding "so far as we can tell, it is roughly compatible with the experimental data". Few referees would now let that pass, nor would they be happy with the much quoted "It has not escaped our notice that the pairing mechanism we have postulated immediately suggests a possible copying mechanism for the genetic material". "Mere speculation!" would be the complaint.

So why have those informal and, no doubt, genteel ways of deciding what to publish been forsaken? (All the contributions now appearing as Articles or Letters in Nature have been subjected to this kind of external criticism, but with the extra request of referees that they should also advise on the immediate interest of what is offered for publication.)

The circumstance that Nature's editorial staff are mostly not practising scientists is only part of the explanation. Even the gigantic increase in recent decades of the volume of material seeking an outlet in print, and the steady process by which sub-specialities become sub-sub-specialities, do not in themselves account for what has happened. More subtle changes in the nature of scientific publications are more telling.

First, and to the credit of the scientific community, there has been sustained and deliberate pressure to improve the standards of publications. When there is so much talk of how the literature is corrupted by false and even fraudulent reports, this beneficent tendency is too easily forgotten. People no longer wish to waste their time reading research reports which include so little data that their conclusions cannot be verified. Nor do they rejoice when the authors of entirely respectable research go on to speculate about the general implications of what they have done (which is generally distrusted because it is a means by which the importance of a piece of research may be magnified artificially).

The other side of that coin, of course, is that research reports have become less palatable as literature. Most articles in most journals can now be read without difficulty only by those who happen to be working in a closely related field. But need the rule that rigour means difficulty of understanding be as closely followed as it is? In its admirable pursuit of meticulousness, the scientific community is in danger of overlooking the not necessarily incompatible and primary function of the literature, which is communication.

Another and more insidious pressure on the system is competitiveness people's anxiety to be the first in print with reports of important or even unimportant discoveries. Everybody knows that the stakes are high. Publications, especially in journals known to be rigorous in their selection of what they publish, do determine promotion prospects and influence the likelihood of continuing research support.

But competition is in danger of getting out of hand. Journals such as this are now often presented with the uncomfortable need to decide whether loose use of language, or inadequate experimental data, are consequences of authors' haste or of some more sinister concealment of the whole truth. This does not happen often, but that it should happen at all is a serious matter, requiring the cultivation, by referees and all others concerned, of an over-suspicious frame of mind.

That, of course, is merely another reason why some means must be sought for abating the pressure to publish quickly, or to publish in leading journals, or even to publish at all. In the long run, there will have to be better means by which the academic community can make judgements of the quality of its members. One benefit would be that the literature would become more like literature, but nobody appears to have assessed how great would be the benefit if much of the time that referees now voluntarily lavish on other people's manuscripts could be used for better things. John Maddox 